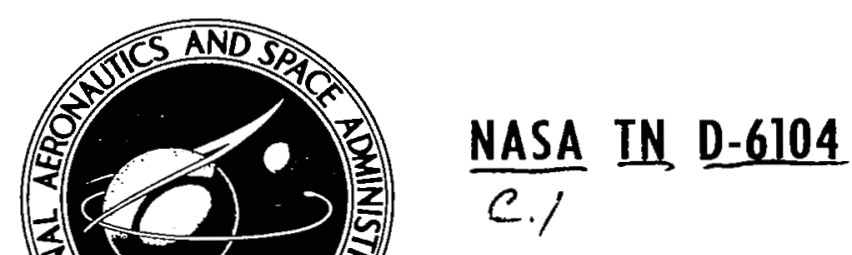

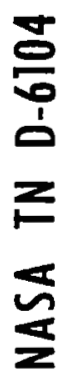

\title{
AN APPROACH TO THE DETERMINATION \\ OF AIRCRAFT HANDLING QUALITIES \\ BY USING PILOT TRANSFER FUNCTIONS
}

by James J. Adams and Howard G. Hatch, Jr.

Langley Research Center

Hampton, Va. 23365

national aeronautics and SPACE adMINISTRATION - WASHINGTON, D. C. - JANUARY 1971 


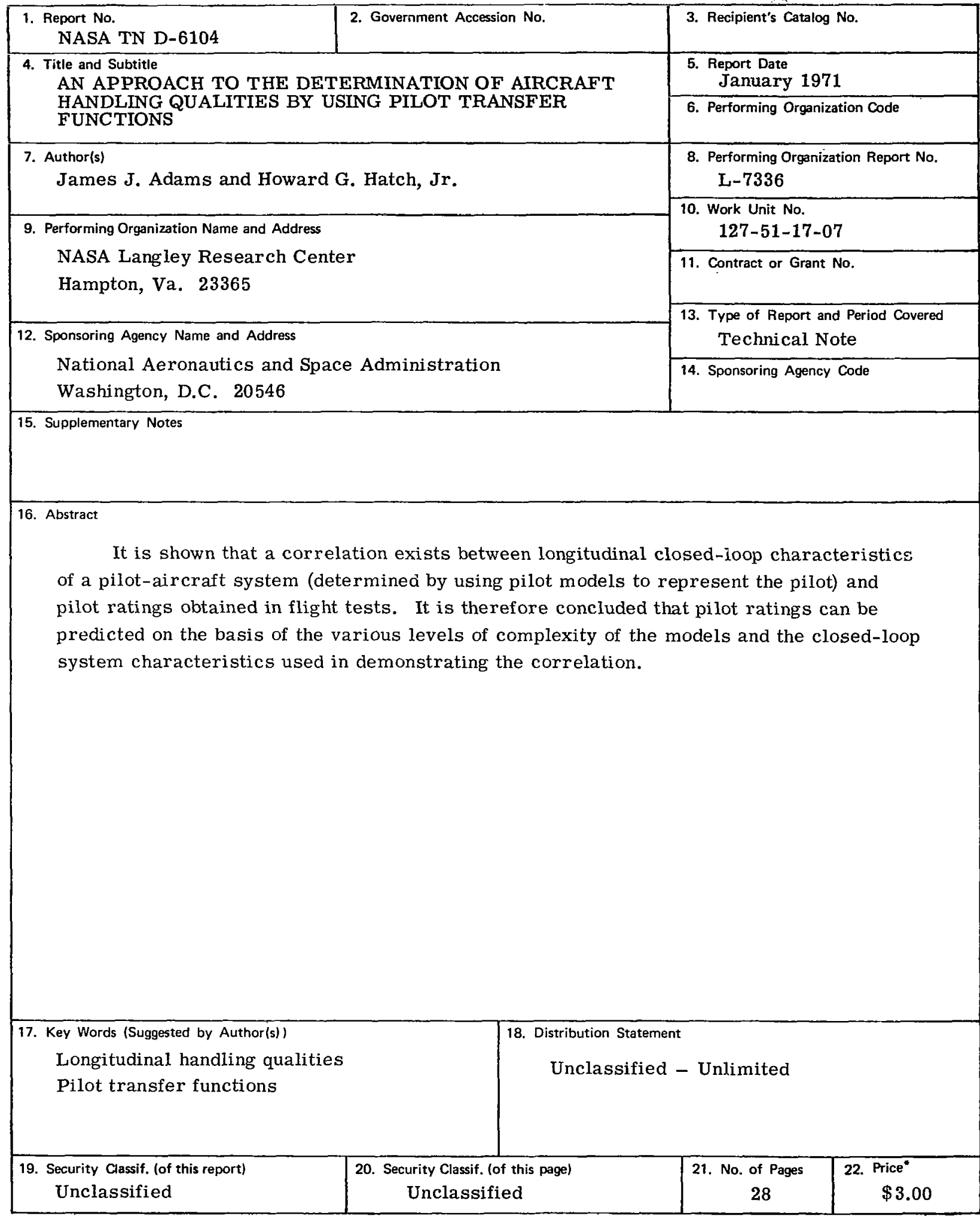

"For sale by the National Technical Information Service, Springfield, Virginia 22151 


\title{
AN APPROACH TO THE DETERMINATION \\ OF AIRCRAFT HANDLING QUALITIES BY USING \\ PILOT TRANSFER FUNCTIONS
}

\author{
By James J. Adams and Howard G. Hatch, Jr. \\ Langley Research Center
}

\section{SUMMARY}

It is shown that a correlation exists between longitudinal closed-loop characteristics of a pilot-aircraft system (determined by using analytical expressions for pilot response along with the analytical expression for the aircraft response) and pilot ratings obtained in many previous flight and simulation studies. Two levels of preferred pilot response used in the computations are (1) a static gain and a second-order lag function with a lag time constant of 0.2 second; and (2) a static gain, a lead time constant of 1 second, and a lag time constant of 0.2 second.

If a system response with a pitch-angle time constant of no more than 2.6 seconds and with a stable oscillatory angle-of-attack mode of motion having a period of no more than 2.5 seconds can be achieved with the first-level pilot model, the pilot rating for the vehicle is satisfactory. Further, if an altitude response with a stable oscillatory mode of motion with a period of no more than 5 seconds can be achieved, the vehicle is rated satisfactory. If the second-level pilot model is required to achieve these system response characteristics, the vehicle is rated acceptable-unsatisfactory.

\section{INTRODUCTION}

It has been shown in references 1 and 2 that models of human response together with models or equations of motion of the vehicle can be used to predict system performance of manually controlled vehicles. It would be beneficial if these pilot models could also be used to predict pilot acceptance, or rating, of future vehicles. This thought has been discussed previously in reference 3. Since a large amount of previously obtained data is available on pilot ratings of aircraft as functions of aircraft characteristics, criteria for predicting pilot ratings are established in this paper by showing the correlation between calculated characteristics of the pilot-vehicle system (determined by using pilot models) and the previously obtained pilot ratings of aircraft. The criteria that are developed involve both specified levels of preferred pilot response characteristics and 
specified closed-loop characteristics of the pilot-vehicle system. The emphasis in this paper is on pilot ratings for aircraft longitudinal control, but the procedure should be applicable to other control situations.

\section{SYMBOLS}

Values are given in both SI and U.S. Customary Units. The measurements and calculations were made in U.S. Customary Units.

$\mathrm{C}_{\mathrm{L}} \quad$ lift coefficient

$\mathrm{C}_{\mathrm{L}_{\alpha}}=\frac{\partial \mathrm{C}_{\mathrm{L}}}{\partial \boldsymbol{\alpha}}$

$\mathrm{C}_{\mathrm{L}_{\delta_{\mathrm{e}}}}=\frac{\partial \mathrm{C}_{\mathrm{L}}}{\partial \delta_{\mathrm{e}}}$

$\mathrm{C}_{\mathrm{m}} \quad$ pitching-moment coefficient

$\mathrm{C}_{\mathrm{m}}=\frac{\partial \mathrm{C}_{\mathrm{m}}}{\partial(\mathrm{q} \mathrm{c} / 2 \mathrm{~V})}$

$\mathrm{C}_{\alpha}=\frac{\partial \mathbf{C}_{\mathrm{m}}}{\partial \alpha}$

$\mathrm{C}_{\mathrm{m}_{\delta_{e}}}=\frac{\partial \mathbf{C}_{\mathrm{m}}}{\partial \delta_{\mathrm{e}}}$

c mean aerodynamic chord, $m$ (ft)

e displayed error, rad

h altitude, $\mathrm{m} \quad(\mathrm{ft})$

$\mathrm{h}_{\mathrm{c}}, \mathrm{h}_{\mathrm{e}} \quad$ altitude command and error, respectively, $\mathrm{m}$ (ft)

$\mathrm{I}_{\mathrm{Y}} \quad$ moment of inertia, $\mathrm{kg}-\mathrm{m}^{2} \quad\left(\mathrm{slug}-\mathrm{ft}^{2}\right)$

K general gain 


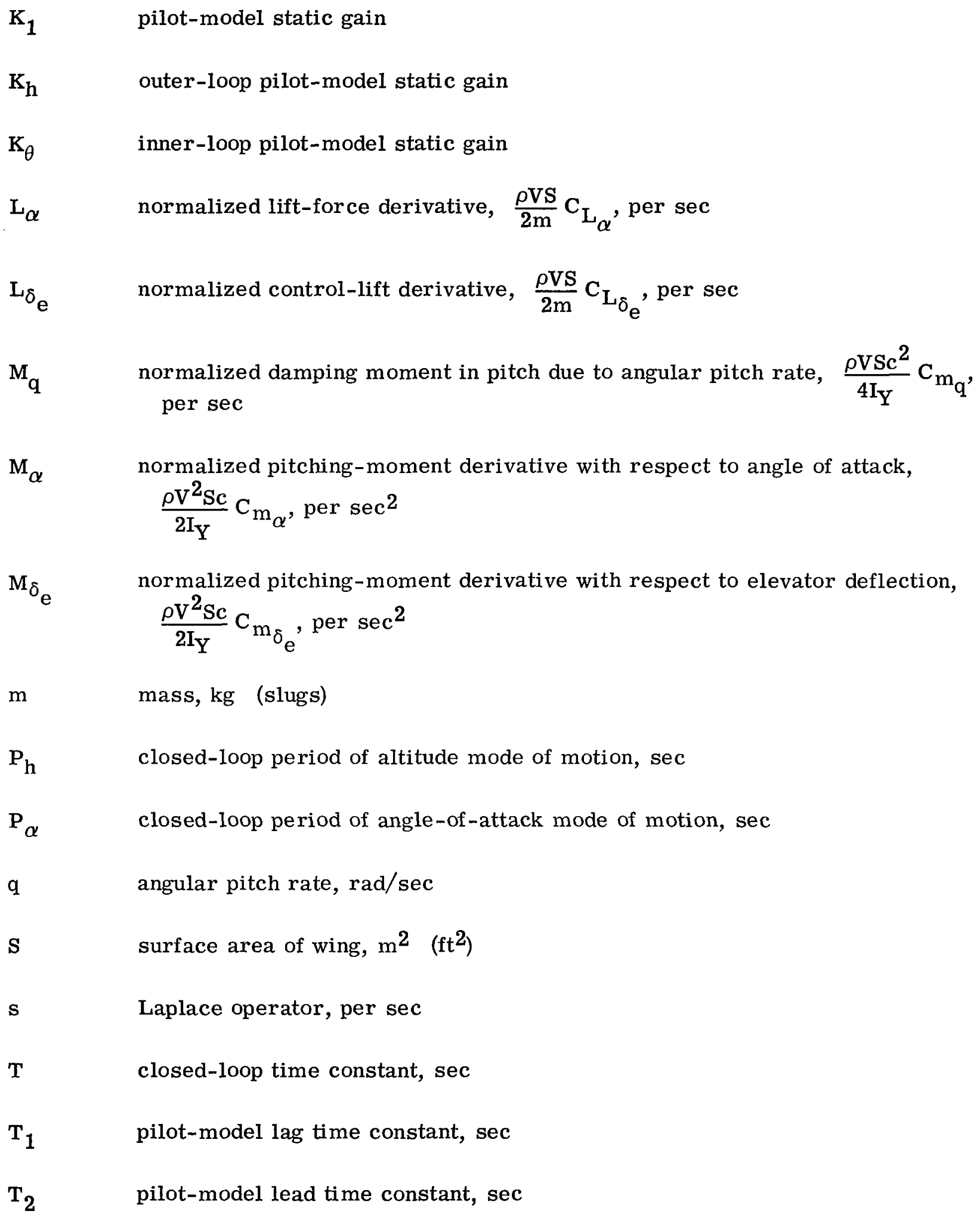




\begin{tabular}{|c|c|}
\hline $\mathrm{T}_{\theta, 2}$ & open-loop aircraft lead time constant, sec \\
\hline t & time, sec \\
\hline V & velocity, $\mathrm{m} / \mathrm{sec}(\mathrm{ft} / \mathrm{sec})$ \\
\hline $\mathrm{x}_{\mathrm{e}}$ & displacement error, $m \quad(f t)$ \\
\hline$\alpha$ & angle of attack, rad (except where otherwise noted) \\
\hline$\gamma$ & flight-path angle, rad \\
\hline$\delta$ & control deflection, rad \\
\hline$\delta_{\mathrm{e}}$ & elevator control deflection, rad \\
\hline$\zeta$ & damping ratio \\
\hline$\zeta_{\mathrm{h}}$ & damping ratio of altitude mode of motion \\
\hline$\zeta_{\alpha}$ & damping ratio of angle-of-attack mode of motion \\
\hline$\theta$ & pitch angle, rad (except where otherwise noted) \\
\hline$\theta_{c}, \theta_{e}$ & pitch-angle command and error, respectively, rad \\
\hline$\rho$ & air density, $\mathrm{kg} / \mathrm{m}^{3} \quad\left(\right.$ slugs $\left./ \mathrm{ft}^{3}\right)$ \\
\hline$\omega_{\mathrm{c}}$ & closed-loop control frequency, $\mathrm{rad} / \mathrm{sec}$ \\
\hline$\omega_{\mathrm{f}}$ & control-actuator undamped natural frequency, $\mathrm{rad} / \mathrm{sec}$ (or cps) \\
\hline$\omega_{\mathrm{h}}$ & closed-loop altitude frequency, $\mathrm{rad} / \mathrm{sec}$ \\
\hline$\omega_{\mathrm{n}}$ & open-loop aircraft undamped natural frequency, rad/sec \\
\hline$\omega_{\alpha}$ & closed-loop angle-of-attack frequency, rad/sec \\
\hline
\end{tabular}


Abbreviation:

PR. pilot rating

Single and double dots over symbols denote first and second derivatives, respectively, with respect to time.

\section{PILOT MODELS}

\section{Single-Loop Control Tasks}

For single-loop control tasks, the pilot model used herein consists of the following elements: a static gain and a lead time constant, which constitute a mentally commanded control deflection; and a second-order, critically damped lag function, which represents the dynamic response of the arm in executing the command for the control deflection. In transfer-function form the model is

$$
\frac{\delta}{\mathrm{e}}=\frac{\mathrm{K}_{1}\left(1+\mathrm{T}_{2} \mathrm{~s}\right)}{\left(1+\mathrm{T}_{1} \mathrm{~s}\right)^{2}}
$$

Typical measured pilot transfer functions showing the response of the pilots when controlling three different plants are shown in table I. Two examples are given for each of the plant dynamics to illustrate the range of coefficients that occur.

TABLE I

\section{MEASURED PILOT RESPONSE}

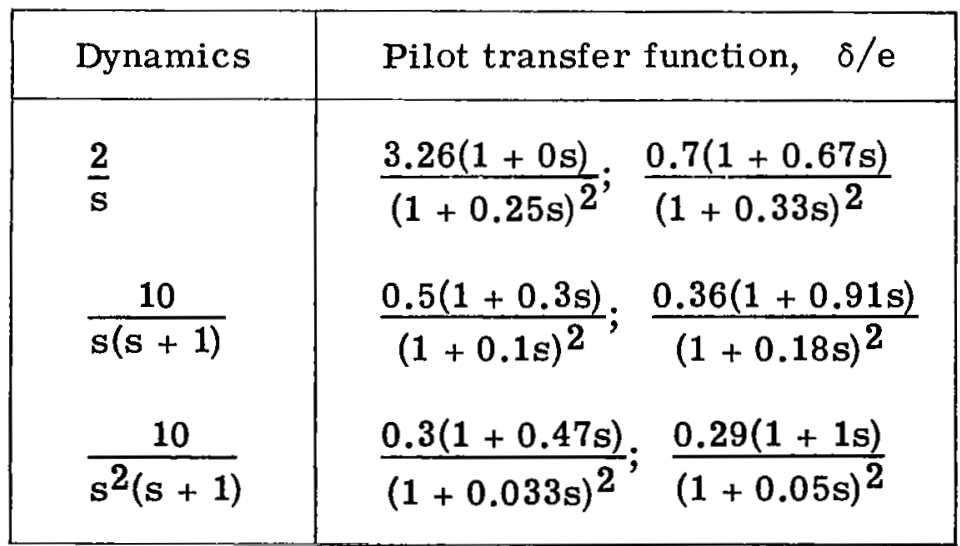

Average values derived from all the appropriate tests reported in references 4, 5 , and 6 for the lead and lag time constants are presented in table $\Pi$. 
TABLE II

\section{AVERAGE VALUES FOR LEAD AND LAG TIME CONSTANTS}

OF PILOT RESPONSE

\begin{tabular}{|l|c|c|}
\hline Dynamics & $\begin{array}{c}\text { Lead time constant, } \\
\mathrm{T}_{2}, \text { sec }\end{array}$ & $\begin{array}{c}\text { Lag time constant, } \\
\mathrm{T}_{1}, \mathrm{sec}\end{array}$ \\
\hline$\frac{2}{\mathrm{~s}}$ & 0.26 & 0.22 \\
$\frac{10}{\mathrm{~s}(\mathrm{~s}+1)}$ & .92 & .17 \\
$\frac{10}{\mathrm{~s}^{2}(\mathrm{~s}+1)}$ & .97 & .044 \\
\hline
\end{tabular}

It can be seen from these tables that when a pilot is controlling a very easy-to-handle plant, such as a vehicle with pure-rate dynamics $2 / \mathrm{s}$, the lag time constant of the pilot's response $T_{1}$ is as large as 0.33 second, with 0.22 second being the average value; the pilot-model lead time constant $\mathrm{T}_{2}$ is often zero, with the average value being 0.26 second. However, it seems that a pilot will readily add more lead because sometimes a substantial amount is measured for dynamics of $2 / \mathrm{s}$. If the lag of the plant is increased, as for the plant with dynamics of $\frac{10}{s(s+1)}$, lead is always present, and the average value of $\mathrm{T}_{2}$ increases to 0.92 second. When more compensation is required on the part of the pilot to control the system because the plant lag is increased further, the pilot-model lag time constant is reduced. For the type of plant which a human operator is just barely able to control in a stable manner (that is, a plant with dynamics of $\frac{10}{s^{2}(s+1)}$ ), the pilotmodel lag time constant is reduced to 0.044 second. It appears from these data that appropriate steps in pilot adaptation to plant difficulty are first to add lead and, second, to reduce lag.

In one experiment reported in reference 4, pilot response was measured while controlling an aircraft-pitch-response type of plant. The plant dynamics were

$$
\frac{\theta}{\delta}=\frac{10}{s\left(s^{2}+3 s+10\right)}
$$

and the measured pilot transfer function was 


$$
\frac{\delta}{\mathrm{e}}=\frac{0.86(1+0.71 \mathrm{~s})}{(1+0.14 \mathrm{~s})^{2}}
$$

It can be seen from this pilot transfer function that the lag and lead time constants are within the ranges noted in the previous paragraph. It is assumed, therefore, that the maximum and minimum average values for the time constants given in table II also apply to aircraft plant dynamics.

The human pilot provides a static gain $\mathrm{K}_{1}$, which is always adjusted to provide desired closed-loop system response characteristics. That these system characteristics can be identified and defined is shown by the results obtained in reference 4 . In reference 4 a wide variety of plants, control gains, display gains, and subjects were tested. In spite of this great variety of system elements, the dominant closed-1oop system characteristic (the mode of motion which provides the largest contribution to the time response of the system) always fell within a very restricted range of period or time constant. For the type of plants considered in reference 4 , that is, plants of the form $\mathrm{K} / \mathrm{s}$ and $\mathrm{K} / \mathrm{s}^{2}$, which have no static stability of their own, the dominant system characteristic was an oscillatory mode of motion. The frequency of this oscillation always fell within the range of from 2 to $4 \mathrm{rad} / \mathrm{sec}$ (that is, the period was around 2 seconds), and the oscillation was always stable. From these results, it is concluded that the pilot uses the dominant system characteristics as the criteria to set his static gain.

The dominant system characteristic is not always an oscillatory mode of motion. With the aircraft-pitch-response type of plant, the dominant closed-loop system characteristic was a first-order mode of motion. (In the case represented by eqs. (2) and (3), the time constant of this first-order response was 1.7 seconds.) There was also an oscillatory mode of motion included in the system response in this case, and this oscillatory mode was stable.

From these examples, it is concluded that the system response which the pilot concerns himself with can be of two different types. If the dominant system characteristic is an oscillatory mode of motion, the pilot is concerned with the frequency and damping of this mode of motion. If the dominant system characteristic is a first-order mode of motion, the pilot is concerned with the time constant of this mode and the stability of the other oscillatory modes of the response. In either case the system time characteristic (period or time constant) that the pilot strives to achieve is around 2 seconds.

\section{Multiloop Control Tasks}

If the control task is a multiloop problem, where there is a second variable (such as altitude or horizontal displacement) which is controlled by the manipulation of an innerloop variable (such as pitch angle), it is necessary to specify an outer-loop pilot model in 
series with the inner-loop pilot model. A block diagram of such a system is shown in figure 1. In this type of system the single-loop results discussed in the previous section are applied to the inner loop.

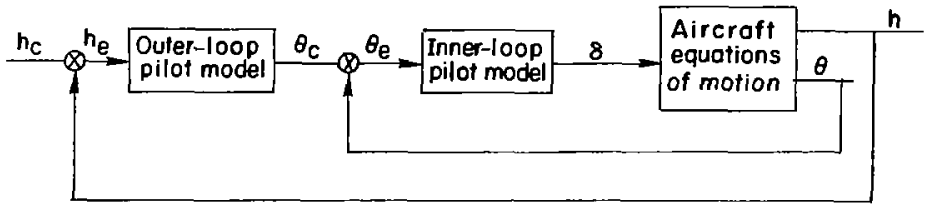

Figure 1.- Block diagram of a typical multiloop system.

Reference 6 shows that in the multiloop control task of lunar module hover, where the outer-loop variable is horizontal translation and the inner-loop variable is pitch angle, the series arrangement of the pilot model does give a true representation of human pilot response. In this task the outer-loop plant dynamics were

$$
\frac{\mathrm{x}_{\mathrm{e}}}{\theta}=\frac{5.36}{\mathrm{~s}^{2}}
$$

and the outer-loop pilot model was

$$
\frac{\theta_{c}}{x_{e}}=\frac{0.009(1+9.2 s)}{(1+0.1 s)^{2}}
$$

It was also shown in reference 6 that the lag function included in the outer-loop pilot model is not really required to properly represent the pilot. The outer-loop variable (horizontal translation) is controlled at such a low frequency that a lag of the magnitude of 0.1 second does not influence the closed-loop response.

Reference 7 has shown similar results for helicopter hover. Again, a series arrangement was used to represent the pilot; the required outer-loop pilot model was

$$
\frac{{ }^{\theta} c}{x_{e}}=0.027(1+0.4 s) e^{-0.08 s}
$$

where a small time delay is used instead of a lag function.

Reference 8 used the series arrangement to represent the pilot in the case of altitude control for an airplane; the required outer-loop pilot model was

$$
\frac{{ }^{\theta} \mathrm{c}}{\mathrm{h}_{\mathrm{e}}}=\frac{0.4}{1+0.1 \mathrm{~s}}
$$

In this case, no lead was required and again a very short lag time constant was included. 
In all three of these references (refs. 6, 7, and 8), the outer-loop variable is controlled at a lower frequency than is the inner-loop variable. Also, when the outer loop is closed around the inner loop, the resulting modes of motion couple with each other, and restrictions on the permissible outer- and inner-loop static gains can result.

\section{Pilot Response Levels}

In the single-loop and multiloop experiments just described, different plant dynamics were used to provide different levels of control difficulty, and the pilot response was determined. On the basis of these results, different levels of preferred pilot response are formulated, and it is hypothesized that these levels will correspond to different levels of pilot ratings. The thought that a pilot would prefer to act as a simple amplifier was first discussed in reference 9. In the present paper this idea is expanded to cover the whole range of pilot opinion. For single-loop, or inner-loop, control, the levels of preferred pilot response are as follows:

(1) The pilot would prefer to operate as a simple amplifier with a lag time constant of 0.2 second. This is a very simple response, achieved by the pilot in a relatively leisurely manner. It is hypothesized that if suitable system response characteristics can be achieved with this pilot response, the system will be judged satisfactory.

(2) If moderate compensation is required on the part of the pilot in order to stabilize the system the compensation takes the form of a lead with a time constant of 1 second, with the lag time constant maintained at 0.2 second. In order to supply this lead the pilot must perform the additional mental task of differentiating the displayed information. It is hypothesized that if suitable system characteristics can be achieved with this pilot response, the system will be judged acceptable-unsatisfactory because of the added required task of differentiating.

(3) If further compensation is required, it is supplied by reducing the lag time constant, with values as low as 0.05 second being obtainable. To achieve this response the pilot must not only perform the additional mental task of differentiating the displayed signal but must also increase his physical activity to obtain the faster control deflection. It is hypothesized that if this compensation is required to stabilize the system, the system will be judged unacceptable.

For outer-loop control, two levels of preferred response are proposed. They are as follows:

(1) The pilot would prefer to operate as a simple amplifier. It does not appear to be necessary to specify any particular value for lag time constant in this case, because the expected values of this constant will not influence system response; therefore, a value of zero is used. If this type of response is all that is required for the outer loop, no degradation of pilot rating will result. 
(2) If compensation is required, it takes the form of lead. Apparently, outer-loop lead time constants can be quite large. If lead is required in the outer-loop pilot model, some, as yet undefined, degradation in rating will occur.

For all levels of pilot response, the model static gain is adjusted to provide the lar gest closed-loop system frequency (the shortest time characteristic) possible while maintaining stability. It is expected that for single-loop or inner-loop variables, a time characteristic of around 2 seconds will constitute a desirable system response and that for outer-loop variables, the time characteristic will be longer than 2 seconds. It will be necessary to determine a suitable value for the time characteristic of the outer-loop variable.

Both single-loop and multiloop systems are examined in this study because both types of system are represented in typical flight tasks. The single-loop, attitude control task corresponds to long-range tracking tasks. The multiloop, altitude control task corresponds to landing-approach tasks and also terrain-following and formation-flying tasks.

\section{PILOT-RATING DATA}

A large amount of data on pilot rating as a function of various aircraft parameters has been accumulated in the past. Perhaps the most fundamental relation is that established between pilot ratings and aircraft longitudinal short-period characteristics $\omega_{\mathrm{n}}^{2}$ and $2 \zeta \omega_{n}$. The boundary dividing pilot ratings of satisfactory ( $P R=1$ to 3.5 ) from acceptable-unsatisfactory $(P R=3.5$ to 6.5$)$ and the boundary dividing ratings of acceptableunsatisfactory from unacceptable ( $P R=6.5$ to 9 ) are shown in figure 2 , where $\omega_{n}^{2}$ is plotted as a function of $2 \zeta \omega_{n}$. (Note that the term acceptable-unsatisfactory is shortened
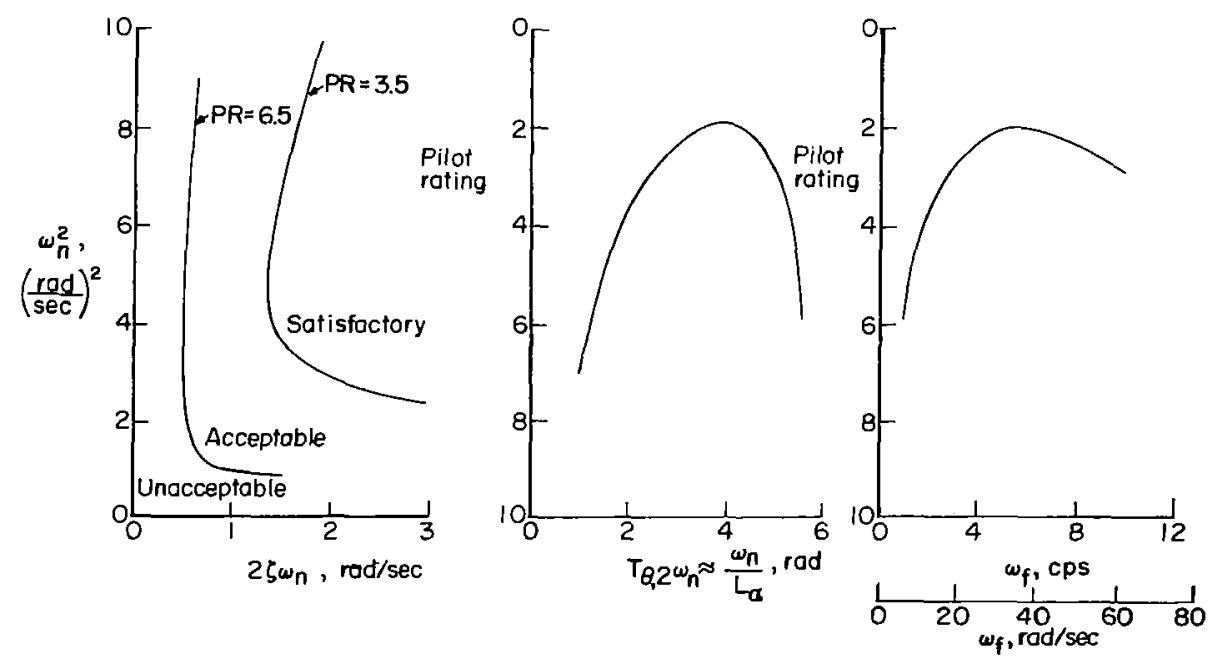

Figure 2.- Pilot ratings as functions of aircraft longitudinal short-period characteristics $\omega_{n}^{2}$ and $2 \zeta \omega_{n}$, of $I_{\alpha}$, and of $\omega_{f}$. 
and just the word acceptable is used to denote this rating.) These boundaries were taken from reference 10 for a landing condition with good (front-side) drag characteristics that is, with drag that increases with increases in speed.

Pilot rating has also been shown to be a function of

$$
\frac{1}{T_{\theta, 2}}=\frac{M_{\delta_{e}} L_{\alpha}-L_{\delta_{e}} M_{\alpha}}{M_{\delta_{e}}}
$$

Since $\mathrm{L}_{\delta_{\mathrm{e}}}$ is usually small,

$$
\frac{1}{\mathrm{~T}_{\theta, 2}} \approx \mathrm{L}_{\alpha}
$$

The relationship of pilot rating to $\mathrm{T}_{\theta, 2}$ has been defined in several ways. In reference 11, where the flight tasks include both altitude and attitude control, it is defined with the use of the parameter $T_{\theta, 2} \omega_{n}$; use of the parameter $T_{\theta, 2} \omega_{n}$ causes the data to coalesce to the curve shown in the second part of figure 2. The data of reference 11 indicate that the best pilot ratings are obtained when $T_{\theta, 2} \omega_{n}=4$ and that the ratings become less favorable for higher or lower values of $T_{\theta, 2} \omega_{n}$. However, a question as to whether the ratings do really become less favorable for the high values of $T_{\theta, 2} \omega_{n}$ has been raised in other investigations (e.g., ref. 3).

Pilot rating has been shown to be a function of control-actuator dynamics also. Reference 12, which is a simulator study, shows that when second-order elevator actuators are inserted into an aircraft longitudinal control system, pilot ratings can be affected. For example, as is shown in the third part of figure 2 (taken from ref. 12), if the natural frequency of the actuator $\omega_{f}$ is less than $3 \mathrm{cps}(20 \mathrm{rad} / \mathrm{sec})$ the rating of the otherwise good aircraft is seriously degraded.

The purpose of the present study is to show that characteristics of the pilot-aircraft system, obtained by using the various levels of preferred pilot response defined in the preceding section, correlate with the pilot ratings as functions of $\omega_{n}^{2}$ and $2 \zeta \omega_{n}$, of $\mathbf{T}_{\theta, 2}$, and of actuator dynamics.

\section{AIRCRAFT AND SYSTEMS REPRESENTATION}

The aircraft is represented by the two-degree-of-freedom longitudinal equations of motion

$$
\dot{\alpha}-\dot{\theta}=-\mathrm{L}_{\alpha} \alpha
$$


and

$$
\ddot{\theta}=\mathrm{M}_{\mathrm{q}} \dot{\theta}+\mathrm{M}_{\alpha} \alpha+\mathrm{M}_{\delta}{ }_{\mathrm{e}} \mathrm{e}
$$

and by the relationship for altitude

$$
\grave{\mathrm{h}}=\mathrm{V}(\theta-\alpha)
$$

Two different values of $\mathrm{L}_{\alpha}$ were used in the investigation - a typical low-speed value $\mathrm{L}_{\alpha}=0.585$ per sec and a high-speed value $\mathrm{L}_{\alpha}=1.3$ per sec. The value of $\mathbf{M}_{\delta_{e}}$ was arbitrarily assumed to be $1.0 \mathrm{per} \mathrm{s^{2 }}$. The values of $\mathrm{M}_{\mathrm{q}}$ and $\mathrm{M}_{\alpha}$ were adjusted to provide a wide range of aircraft short-period characteristics $\omega_{n}^{2}$ and $2 \zeta \omega_{n}$. An example of the performance of the pilot-aircraft system is given in appendix $A$.

\section{ANALYSIS}

\section{Method}

Under the hypothesis of this paper, a given aircraft in a given flight condition is rated satisfactory if suitable closed-loop system response characteristics can be achieved by using a pilot model with zero lead and an inner-loop (or single-loop) lag time constant of 0.2 second. No restrictions are placed on pilot-model static gain, but the limitations on suitable system response characteristics must be defined and met. One of the limitations used is that all system oscillatory modes must be at least neutrally stable. This minimum damping requirement is used because of the indication in previous investigations on pilot response that a human pilot will strive to achieve certain closedloop system frequencies even if system damping must be sacrificed. Determination of these desired frequencies (or system time characteristics) is needed to complete the definition of suitable system response characteristics. For this purpose an exploratory analog computer study was made to determine the response of the pilot-aircraft system for a wide variety of combinations of $\omega_{n}^{2}$ and $2 \zeta \omega_{n}$, with $L_{\alpha}$ set equal to 0.585 per sec. In this process a trial-and-error adjustment was made of the pilot-model static gains to minimize the dominant-mode time characteristics while maintaining at least neutrally stable system response. The time characteristics thus determined for values of $\omega_{n}^{2}$ and $2 \zeta \omega_{n}$ in the vicinity of the experimental boundaries between pilot ratings of satisfactory and acceptable (that is, at $\mathrm{PR}=3.5$ ) should then define the minimum suitable system response.

First, the altitude response obtained by using the multiloop system shown in figure 3 was determined. With this system there were two dominant oscillatory modes 


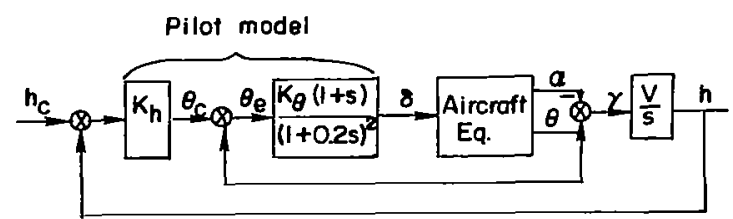

Figure 3.- System block diagram.

of motion - an altitude mode of motion which had a relatively long period and an angleof-attack mode of motion. There was also a high-frequency, well damped control mode of motion which did not contribute in any significant way to the closed-loop time response of the system.

When aircraft with high values of $\omega_{n}^{2}$ were considered, the determination of the best response was very simple and straightforward because the outer loop did not couple with the inner loop in any degrading manner and because the frequency of the inner-loop angle-of-attack mode of motion was always higher than was believed necessary to satisfy a pilot's desire for adequate performance. That is, the period, or time characteristic, of the angle-of-attack mode of motion was less than 2 seconds. Therefore, the innerloop static gain was adjusted to be as high as it could be without making the angle-of attack mode of motion unstable. In this way the maximum amount of compensation was provided for the outer-loop closure. Then the static gain of the outer loop was increased until the altitude mode of motion was neutrally stable. In this way the minimum period of the altitude mode of motion that could be achieved with the first-level pilot model was determined.

For aircraft with low values of $\omega_{n}^{2}$, determining the best response was more involved for two reasons. First, the frequency of the angle-of-attack mode of motion was low, and the inner-loop closure had to be used to increase this frequency to an acceptable value. Second, the outer-loop closure destabilized the angle-of-attack mode of motion. Therefore, a compromise was necessary to achieve a suitable system response.

The results of these trial-and-error procedures are shown in figure 4 , where the periods of the two modes of motion are noted in the plot of $\omega_{n}^{2}$ as a function of $2 \zeta \omega_{n}$ (in the location of $\omega_{n}^{2}$ and $2 \zeta \omega_{n}$ for which they were obtained) together with the pilotrating boundary from reference 10 . The periods of the modes of motion are given instead of the frequencies because it is believed that the periods could be more easily visualized and would therefore be more meaningful. For high values of $\omega_{n}^{2}$ the period of the altitude mode of motion varied from 10 seconds when $2 \zeta \omega_{n}$ was low to 4 seconds when $2 \zeta \omega_{n}$ was high. The period of the angle-of-attack mode of motion was very short over the entire range of $2 \zeta \omega_{n}$, the indication being that control on angle of attack was very tight. From these results an altitude-mode-of-motion period of about 5 seconds 


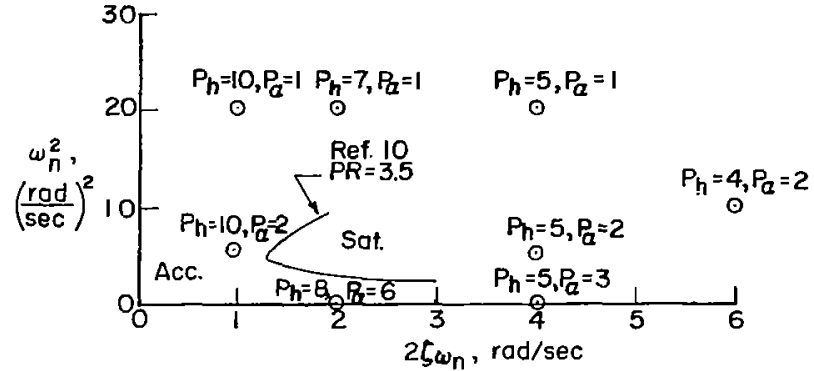

Figure 4.- Results of trial-and-error procedure for obtaining best closed-loop system response for altitude control, with first-level pilot model used. (Values of $P_{h}$ and $P_{\alpha}$ are in seconds; the pilot-rating boundary from ref. 10 is presented for comparison.)

was arbitrarily selected as being a suitable value to use to separate satisfactory from acceptable system response. For low values of $\omega_{n}^{2}$ it was found that a 5-second altitude-mode-of-motion period could be obtained in combination with an angle-of-attackmode-of-motion period of 2 or 3 seconds. It was believed that this angle-of-attack-modeof-motion period was in the range of closed-loop system response that would be desired by a human pilot for an inner-loop variable.

It was also concluded from these calculations that in the plot of $\omega_{n}^{2}$ as a function of $2 \zeta \omega_{n}$, there were two distinct regions with different combinations of critical closedloop factors. For the high values of $\omega_{n}^{2}$ the period of the altitude mode of motion and the damping of both the altitude mode of motion and the angle-of-attack mode of motion appeared to be the critical factors; the period of the angle-of-attack mode of motion and both the period and damping of the control mode of motion seemed to be satisfactory without further consideration. For the low values of $\omega_{n}^{2}$ the periods of the altitude and the angle-of-attack modes of motion and the damping of the angle-of-attack mode of motion were the critical factors.

To determine attitude response, the outer loop of the system shown in figure 3 was discarded and just the inner loop was used. The procedure followed was similar to that described for altitude response. In this case the dominant system modes were a firstorder pitch-angle response and an oscillatory angle-of-attack mode. For high values of $\omega_{\mathrm{n}}^{2}$ the critical factors were the time constant of the pitch-angle mode of motion and the damping of the angle-of-attack mode of motion. For low values of $\omega_{\mathrm{n}}^{2}$ the critical factors were the period and damping of the angle-of-attack mode of motion. The results of the trial-and-error procedure for obtaining the best system response are shown in figure 5. For high values of $\omega_{\mathrm{n}}^{2}$ the pitch-angle time constant varied from 6.3 seconds when $2 \zeta \omega_{n}$ was low to 2.6 seconds when $2 \zeta \omega_{n}$ was high. When $\omega_{n}^{2}$ was low, the period of the angle-of-attack mode of motion was around 2.5 seconds. 


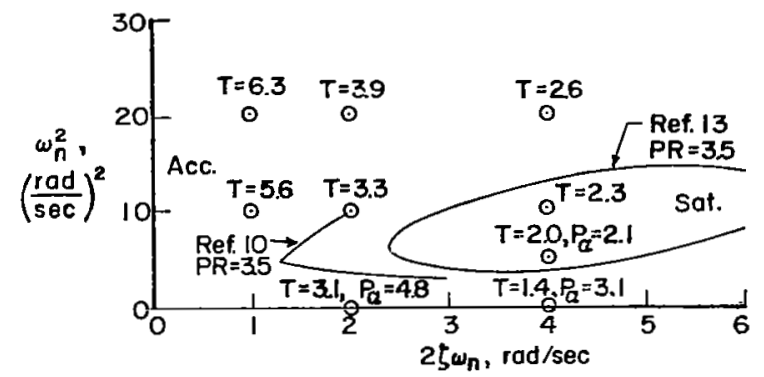

Figure 5.- Results of trial-and-error procedure for obtaining best closed-loop system response for attitude control, with first-level pilot model used. (Values of $T$ and $P_{\alpha}$ are in seconds; the pilot-rating boundaries from refs. 10 and 13 are presented for comparison.)

Also shown in figure 5 is the pilot-rating boundary from reference 10 . However, since this boundary was derived from tests in which the task was to control altitude (that is, to follow a glide slope), it may not be appropriate for comparing with attitude control. Therefore, a boundary published in reference 13 is also presented. The control task in reference 13 was primarily long-range tracking at low speed and therefore corresponds to the computed conditions. A comparison of these two experimental boundaries with the computed results and with results from previous investigations of pilot response (which indicated that a human pilot desires a time characteristic of around 2 seconds for a single-loop system response) leads to the selection of a pitchangle time constant of 2.6 seconds along with neutral stability for the angle-of-attack mode of motion for the boundary conditions for high values of $\omega_{n}^{2}$ and to the selection of an angle-of-attack period of 2.5 seconds and neutral stability for low values of $\omega_{n}^{2}$.

With the values of suitable closed-loop system characteristics determined, the synthesis method described in reference 14 was used to compute the curves which would satisfy these specifications. With this method it is possible to specify any number of desired closed-loop system characteristics, provided that an equal number of open-loop factors are left free to adjust. Values for the open-loop factors that are required to meet the specified closed-loop characteristics are determined. In the present analysis the pilot-model static gains are used as free control factors. Also, to define boundaries, a series of values for $\omega_{n}^{2}$ could be given, with the value of $2 \zeta \omega_{n}$ left free to adjust to a required value. Or $2 \zeta \omega_{n}$ could be given, and $\omega_{n}^{2}$ determined. Both $\omega_{n}^{2}$ and $2 \zeta \omega_{n}$ can be related to aircraft stability derivatives, as shown by the following equations:

$$
\begin{aligned}
& \omega_{\mathrm{n}}^{2}=-\mathrm{L}_{\alpha} \mathrm{M}_{\mathrm{q}}-\mathrm{M}_{\alpha} \\
& 2 \zeta \omega_{\mathrm{n}}=\mathrm{L}_{\alpha}-\mathrm{M}_{\mathrm{q}}
\end{aligned}
$$


Therefore, for altitude control it was possible to specify either of the two following combinations of closed-loop system characteristics:

(1) A period of 5 seconds for the altitude mode of motion and zero damping for both the altitude mode of motion and the angle-of-attack mode of motion $\left(\mathrm{P}_{\mathrm{h}}=5\right.$ seconds; $\left.\zeta_{\mathrm{h}}=0 ; \zeta_{\alpha}=0\right)$

(2) A period of 5 seconds for the altitude mode of motion and a period of 2.5 seconds and zero damping for the angle-of-attack mode of motion $\left(P_{h}=5\right.$ seconds; $\mathrm{P}_{\alpha}=2.5$ seconds; $\left.\zeta_{\alpha}=0\right)$

For attitude control the two sets of closed-loop system characteristics which could be specified were the following:

(1) A pitch-angle time constant of 2.6 seconds and zero damping for the angle-ofattack mode of motion ( $\mathrm{T}=2.6$ seconds; $\left.\zeta_{\alpha}=0\right)$

(2) A period of 2.5 seconds and zero damping for the angle-of-attack mode of motion ( $\mathrm{P}_{\alpha}=2.5$ seconds; $\left.\zeta_{\alpha}=0\right)$

It was believed that these combinations of closed-loop characteristics would define all pilot-rating boundaries.

Table III presents some sample solutions for altitude control. Presented is a complete listing of the open-loop aerodynamic parameters and pilot-model static gains that were determined by the computations and of the closed-loop characteristics, both the ones specified and the remaining ones that were left free. Solutions are considered suitable only if the unspecified closed-loop characteristics are such that they would make negligible contributions to the time response of the system.

TABLE III

COMPUTED SYSTEM PARAMETERS FOR ALTITUDE CONTROL

$\left[L_{\alpha}=0.585\right.$ per sec; first-level pilot model $]$

\begin{tabular}{|c|c|c|c|c|c|c|c|c|c|c|c|}
\hline \multicolumn{6}{|c|}{ Open-loop parameters } & \multicolumn{6}{|c|}{ Closed-loop characteristics } \\
\hline$\omega_{n}^{2}$ & $2 \zeta \omega_{n}$ & $\mathrm{M}_{\alpha}$ & $\mathbf{M}_{\mathrm{q}}$ & $\mathrm{K}_{\theta}$ & $\mathrm{K}_{\mathrm{h}} \mathrm{V}$ & $\omega_{h}$ & $2 \zeta \omega_{\mathrm{h}}$ & $\omega_{\alpha}$ & $2 \zeta \omega_{\alpha}$ & $\omega_{c}$ & $2 \zeta \omega_{c}$ \\
\hline 0.63 & 6.0 & 2.54 & -5.41 & 23.8 & 2.02 & 1.26 & 0.43 & 2.5 & 0 & 8.4 & 15.4 \\
\hline 1.62 & 5.0 & .97 & -4.41 & 20.1 & 2.14 & & .36 & & & 8.0 & 14.6 \\
\hline 2.62 & 4.0 & -.62 & -3.41 & 16.4 & 2.32 & & .29 & & & 7.4 & 12.7 \\
\hline 3.61 & 3.0 & -2.20 & -2.41 & 12.6 & 2.60 & & .19 & & & 6.9 & 12.8 \\
\hline 4.62 & 2.0 & -3.80 & -1.41 & 8.9 & 3.15 & $\downarrow$ & .04 & $\downarrow$ & $\downarrow$ & 6.4 & 12.0 \\
\hline 30 & 3.2 & -28.5 & -2.62 & 38.8 & 4.41 & 1.26 & 0 & 5.22 & 0 & 7.6 & 13.2 \\
\hline 25 & 3.18 & -23.5 & -2.60 & 33.4 & 4.31 & & & 4.84 & | & 7.6 & 13.2 \\
\hline 20 & 3.10 & -18.5 & -2.52 & 27.8 & 4.19 & & & 4.43 & & 7.4 & 13.1 \\
\hline 15 & 2.92 & -13.6 & -2.34 & 21.9 & 4.02 & & & 3.96 & & 7.2 & 12.9 \\
\hline 10 & 2.56 & -8.84 & -1.98 & 15.6 & 3.78 & & & 3.38 & & 6.9 & 12.4 \\
\hline 5 & 1.79 & -4.29 & -1.21 & 8.2 & 3.38 & $\downarrow$ & $\downarrow$ & 2.54 & $\downarrow$ & 6.3 & 11.7 \\
\hline
\end{tabular}


Results

Effects of airplane short-period characteristics.- The computed curves (determined by using the synthesis method) which satisfy the closed-loop system characteristics for altitude control are shown in figure 6. The first-level pilot model, as described in the section on pilot models, was used. The pilot-rating boundary from reference 10 is also presented.

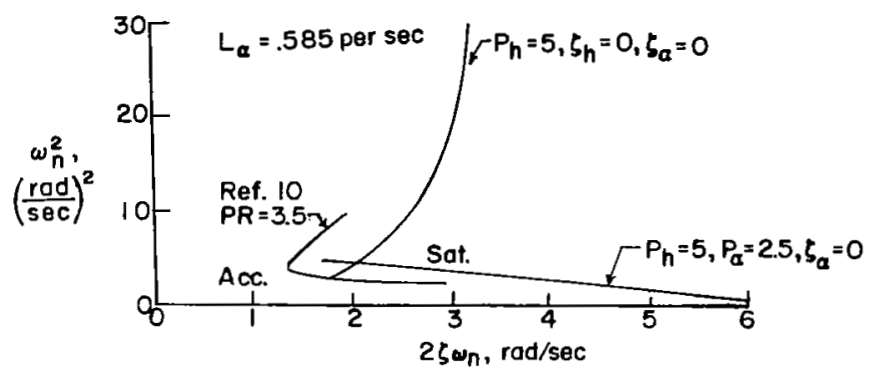

Figure 6. - Comparison of the curves computed by using first-level pilot model (no lead) to provlde specified closed-loop system characteristics for altitude control with the pilot-rating boundary from reference 10 . (Values of $P_{h}$ and $P_{\alpha}$ are in seconds.)

It can be seen that the system requirement $P_{h}=5$ seconds, $\zeta_{h}=0, \zeta_{\alpha}=0$ defines a curve that agrees well with the upper branch of the pilot-rating boundary and that the requirement $P_{h}=5$ seconds, $P_{\alpha}=2.5$ seconds, $\zeta_{\alpha}=0$ defines a curve that agrees well with the lower branch. The nature of these two curves seems to agree with the detailed pilot comments that result from flight tests. When pilots are asked to evaluate an aircraft which has a low short-period natural frequency, they complain that the aircraft seems sluggish and that they have to overdrive it. This comment is believed to correspond to the fact that the short period of the closed-loop system is a critical factor with this type of aircraft and that the inner-loop closure has to be used to decrease this period to 2.5 seconds. When pilots are asked to evaluate an aircraft with a high short-period natural frequency, they complain that the aircraft tends to bobble. This comment is believed to correspond to the conflicting factors that the inner loop must be closed with a high gain to provide adequate compensation for the outer-loop closure but that this high gain also drives the inner loop toward instability. These agreements between the shape and nature of the computed and experimental curves lead to the conclusion that they both describe the same phenomenon.

Next, a 1-second lead time constant was added to the inner-loop pilot model to produce the second-level pilot model, and the synthesis method was used again to define a curve in a plot of $\omega_{\mathrm{n}}^{2}$ as a function of $2 \zeta \omega_{\mathrm{n}}$. With the addition of lead the critical closed-loop factors were $P_{h}=5$ seconds, $P_{\alpha}=2.5$ seconds, and $\zeta_{\alpha}=0$. The curve which satisfies these conditions is shown in figure 7 , and this curve is seen to agree well 
with the pilot-rating boundary between acceptable and unacceptable aircraft. From this result it is concluded that the use of the second-level pilot model to provide the specified closed-loop characteristics can separate acceptable from unacceptable aircraft.

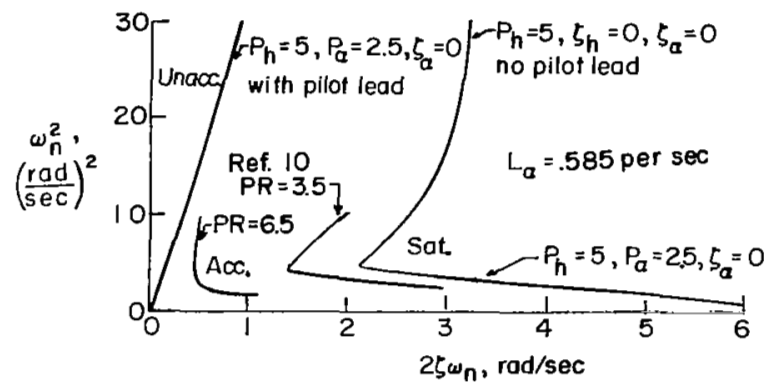

Figure 7.- Comparison of the curves computed by using first-level pilot model (no lead) and second-level pilot model (lead) to provide specified closedloop system characteristics for altitude control with the pilot-rating boundaries from reference 10 . (Values of $P_{h}$ and $P_{\alpha}$ are in seconds.)

The boundary defined by the specification $\mathrm{P}_{\mathrm{h}}=5$ seconds, $\zeta_{\mathrm{h}}=0, \zeta_{\alpha}=0$ was also computed with pilot lead and was found to lie in the same area as the boundary described in the previous paragraph. However, the solutions did not meet all the requirements for this specification because the period of the angle-of-attack mode of motion, which was not specified, was longer than 2.5 seconds. Therefore this boundary was not plotted.

With the linear, constant-coefficient pilot model used in these computations, there is no restriction in the region of low and negative $\omega_{n}^{2}$, and therefore the cutoff for acceptable aircraft near zero frequency that occurs in the experimental data is not predicted. It would appear that some consideration of leaving the aircraft uncontrolled for some length of time should be included in predicting pilot ratings. A consideration of this type would provide a boundary near $\omega_{\mathrm{n}}^{2}=0$.

Next, attitude control determined by using just the inner loop, with no pilot lead, was examined. As can be seen in figure 8 , the closed-loop specifications of $\mathrm{T}=2.6$ seconds, $\zeta_{\alpha}=0$ and $\mathrm{P}_{\alpha}=2.5$ seconds, $\zeta_{\alpha}=0$ result in two curves which, again,

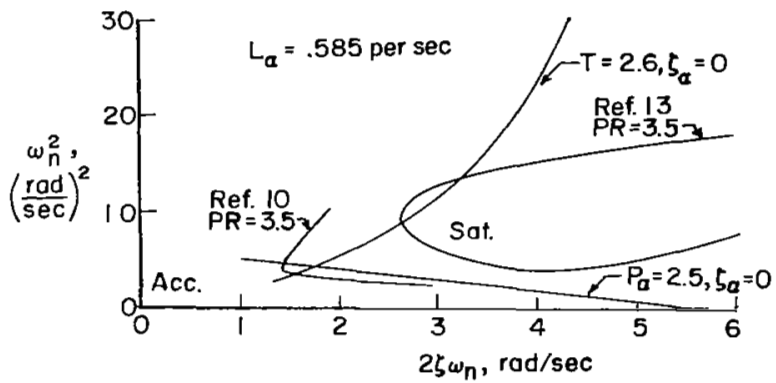

Figure 8.- Comparison of the curves computed by using first-level pilot model (no lead) to provide specified closed-loop system characteristics for attitude control with the pilat-rating boundaries from references 10 and 13 . (Values of $T$ and $P_{\alpha}$ are in seconds.) 
agree well with the pilot-rating boundaries from references 10 and 13. It appears that these specifications, together with the first-level pilot model, will also separate satisfactory from acceptable aircraft.

When lead was added to the pilot model for the attitude control task, the surprising result was that system response was degraded in the region of high $\omega_{n}^{2}$, as is shown in figure 9. As was true for altitude control, the addition of lead eliminated all restriction

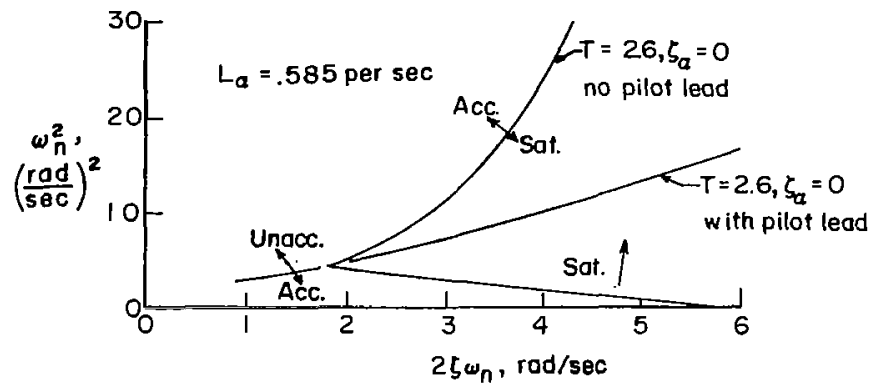

Figure 9.- Effect of lead in pilot model for the attitude control task. (Values of $T$ are in seconds.)

in the region of low and negative $\omega_{n}^{2}$. However, instead of moving the boundary for satisfactory control in the region of high $\omega_{n}^{2}$ to the left, as was the result with altitude control, the boundary was moved to the right. This would seem to be a very confusing situation in which the addition of lead would help the pilot bring the aircraft under better control for altitude control but would degrade the system for attitude control. Pilot comments indicate that an exceptional amount of confusion does exist for aircraft in this region. In reference 15 pilot comments for an aircraft with a normalized lift-force derivative of 0.5 per sec, an undamped natural frequency of $0.7 \mathrm{cps}$, and a damping ratio of 0.3 (see data point in fig. 10) indicate that altitude control was fair whereas attitude control was poor because of a tendency for the aircraft to bobble. The computed results are believed to be in good agreement with the detailed pilot comments, and this agreement emphasizes the fact that, for aircraft in the acceptable region, the task has a noticeable effect on pilot rating.

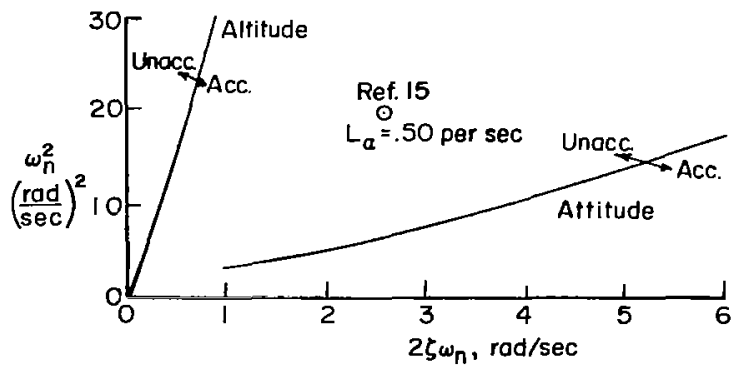

Figure 10.- Comparison of altitude and attitude control boundaries computed by using second-level pilot models. 
Effect of $\mathrm{T}_{\theta, 2}$ or $\mathrm{L}_{\alpha^{*}}{ }^{-}$- Another set of results which can be used to show the validity of the pilot model is the data that relate changes in pilot ratings to changes in $L_{\alpha}$. The effect of $L_{\alpha}$ on pilot ratings has been summarized by the statement that pilots prefer that

$$
\mathrm{T}_{\theta, 2} \omega_{\mathrm{n}} \approx \frac{\omega_{\mathrm{n}}}{\mathrm{L}_{\alpha}}=4 \mathrm{rad}
$$

This equation indicates that for $L_{\alpha}=0.585$ per sec, the preferred value for $\omega_{n}^{2}$ is $5.5\left(\frac{\mathrm{rad}}{\mathrm{sec}}\right)^{2}$. In figures 6 and 8 it can be seen that $\omega_{\mathrm{n}}^{2}=5.5\left(\frac{\mathrm{rad}}{\mathrm{sec}}\right)^{2}$ corresponds to that part of the computed boundary that gives the lowest value of aircraft damping $2 \zeta \omega_{n}$ for satisfactory system response. With $\mathrm{L}_{\alpha}=1.3$ per $\mathrm{sec}$, the handling-quality data indicate that the preferred value for $\omega_{n}^{2}$ increases to $27\left(\frac{\mathrm{rad}}{\mathrm{sec}}\right)^{2}$. The boundaries for the same system characteristics, with no lead in the pilot model, were also calculated with $\mathrm{L}_{\alpha}$ increased to 1.3 per sec. These results for altitude and attitude control are shown, together with the results for $\mathrm{L}_{\alpha}=0.585$ per sec, in figures 11 and 12 , respectively.

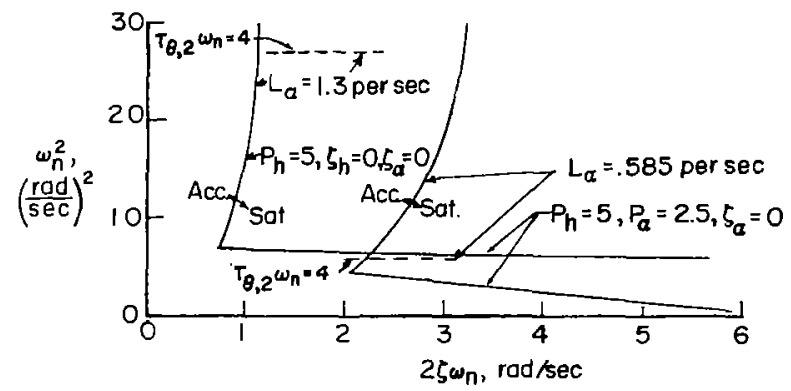

Figure 11.- Comparison of altitude-control boundaries computed by using first-level pilot model for two values of $I_{t}$. (Values of $P_{h}$ and $\mathrm{P}_{\alpha}$ are in seconds; $\mathrm{T}_{\theta, 2} \mathrm{\omega}_{\mathrm{n}}$ is in radians.)

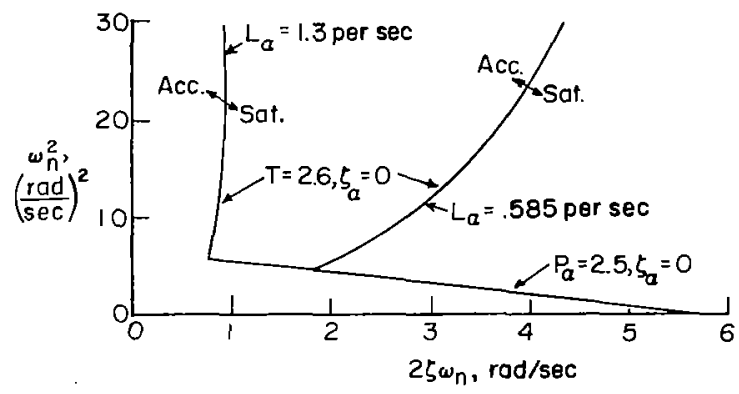

Figure 12.- Comparison of attitude-control boundaries computed by using first-level pilot model for two values of $I_{6}$. (Values of $T$ and $P_{\alpha}$ are in seconds.) 
The compuated system characteristics indicate that the satisfactory area in the plot of $\omega_{n}^{2}$ as a function of $2 \zeta \omega_{n}$ has been greatly expanded in the region of high $\omega_{n}^{2}$, with the location of $T_{\theta, 2} \omega_{n}=4$ being within this expanded area. The satisfactory region is slightly restricted in the region of low $\omega_{n}^{2}$ for the higher value of $L_{\alpha}$. Thus it can be seen that the computations are compatible with the trends shown in the experimental pilot-rating data.

With pilot lead added, the results follow the same trends as noted previously. The computed boundary for altitude control is shown in figure 13, where the addition of lead is seen to move the curve further to the left. A part of this curve is shown dotted for the following reason. For high values of $\omega_{n}^{2}$ the solutions obtained with the synthesis method were suitable in that the period of the angle-of-attack mode of motion, which was not specified for this boundary, was shorter than 2.5 seconds. However, for low values of $\omega_{n}^{2}$ the period of the angle-of-attack mode of motion became longer than 2.5 seconds, and therefore the solutions were not considered suitable and are not shown. However, approximate analog solutions obtained by a trial-and-error method and judged on the basis of the computed time histories indicated that suitable system response could be obtained for aircraft characteristics to the right of the dotted line. These solutions were therefore used to complete the boundary.

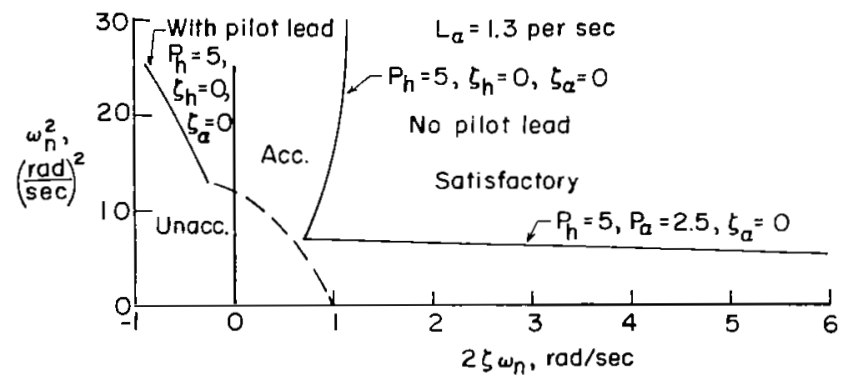

Figure 13.- Comparison of altitude-control boundaries computed by using first-level pilot model (no lead) and second-level pilot model (lead). (Values of $P_{h}$ and $P_{\alpha}$ are in seconds.)

With pilot lead the boundary computed by the synthesis method for the specification $\mathrm{P}_{\mathrm{h}}=5$ seconds, $\mathrm{P}_{\alpha}=2.5$ seconds, $\zeta_{\alpha}=0$ also fell in the same area as the boundary which specified $\mathrm{P}_{\mathrm{h}}=5$ seconds, $\zeta_{\mathrm{h}}=0, \zeta_{\alpha}=0$. However, the control mode of motion that resulted had a very long time characteristic, and therefore the solutions were considered not suitable.

The computed boundary for attitude control, with $L_{\alpha}=1.3$ per sec and with pilot lead, is shown in figure 14. The results follow the same trend as noted for $\mathrm{L}_{\alpha}=0.585$ per sec when pilot lead was added. The addition of lead removes the restrictions for low values of $\omega_{n}^{2}$, but moves the boundary to the right for high values 
of $\omega_{\mathrm{n}}^{2}$. However, the boundaries are less restrictive for $L_{\alpha}=1.3$ per sec (fig. 14) than they were for $L_{\alpha}=0.585$ per sec (fig. 9).

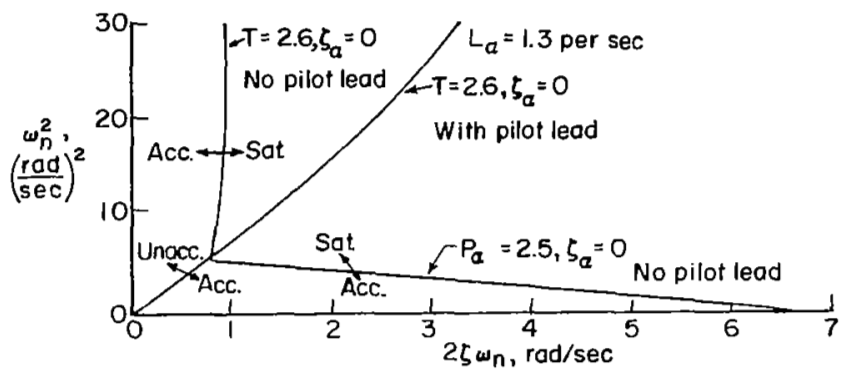

Figure 14.- Comparison of attitude-control boundaries computed by using first-level pilot model (no lead) and second-level pilot model (lead). (Values of $T$ and $P_{\alpha}$ are in seconds.)

Flight tests have been used to define pilot ratings as functions of $\omega_{n}^{2}$ and $2 \zeta \omega_{n}$ and as functions of $T_{\theta, 2}$ and $\omega_{n}$. The previous paragraphs have shown that computed boundaries agree well with these flight data. The combined effects of $\omega_{n}, 2 \zeta \omega_{n}$, and $\mathrm{T}_{\theta, 2}$ have not been systematically studied in flight tests. One of the immediate advantages to be gained from the present investigation is that it indicates the effect of the combination of all three parameters. In fact, the present method can provide answers to the question of pilot ratings for any number of system parameters and can thereby alleviate the need for extensive flight-test programs.

Effect of control-actuator dynamics.- A third influencing factor on pilot ratings that can be checked with the use of pilot models is the degrading effect of inserting controlactuator dynamics in the control system. It has been shown that if the actuator has a natural frequency of less than $20 \mathrm{rad} / \mathrm{sec}$, the pilot ratings are sometimes drastically affected. Therefore, system characteristics were computed with a second-order actuator system inserted in the pilot-aircraft system. The actuator was assumed to have a natural frequency of $10 \mathrm{rad} / \mathrm{sec}$ and a damping ratio of 0.7 , which is the type of actuator response that is very likely to be encountered in a power-boost control system. Attitude control with no pilot lead was examined. For the low value of $\mathrm{L}_{\alpha}$ (that is, $\mathrm{L}_{\alpha}=0.585$ per sec), the boundaries computed with no actuator (perfect response assumed) and with the $10-\mathrm{rad} / \mathrm{sec}$ actuator are presented in figure 15 . It can be seen that the addition of the actuator restricts the satisfactory region, or conversely, for given aircraft short-period characteristics the pilot rating would be degraded. In reference 12 two lowspeed aircraft configurations (configurations $A$ and $B$ ) were tested with variations in the actuator natural frequency, and the locations of these aircraft characteristics are also plotted in figure 15. For configuration B with a very high actuator frequency (essentially perfect response), a pilot rating of 2 (satisfactory) was given. For the same aircraft configuration combined with an actuator frequency of $10 \mathrm{rad} / \mathrm{sec}$, a rating of 3 or 3.5 


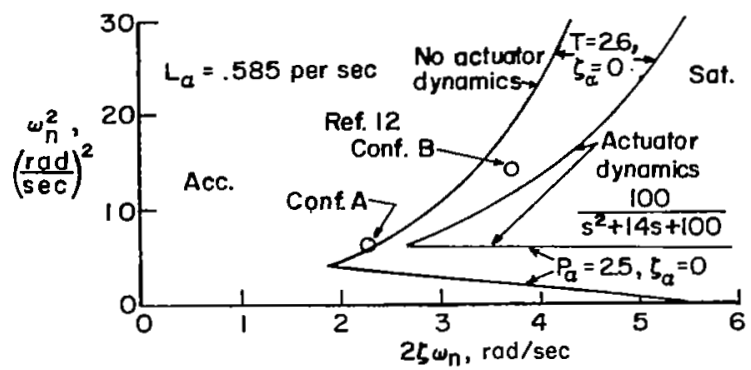

Figure 15.- Effect of actuator dynamics on attitude-control boundaries computed by using first-level pilot model (no lead) with $I_{b c}=0.585$ per sec. (Values of $T$ and $P_{\alpha}$ are in seconds.)

(borderline rating between satisfactory and acceptable) was indicated. The computations show that this aircraft is inside the satisfactory region (a rating of better than 3.5 ) with perfect actuator dynamics and moves outside the satisfactory region when the actuator with the frequency of $10 \mathrm{rad} / \mathrm{sec}$ is added. The experimental and computed results are therefore seen to be in good agreement. For configuration $A$ the pilot ratings changed from 5 to 6 with the addition of the actuator, and this change again agrees with the computed results, although the overall level of the experimentally derived ratings is more towards unsatisfactory than the computed results indicate. It is pointed out in reference 12 that some extenuating circumstances were present that were believed to degrade the overall pilot ratings.

For the high-speed condition ( $\mathrm{L}_{\alpha}=1.3$ per sec), the computed boundaries are presented in figure 16. Again, changes occur in the position of the boundaries when the actuator is added. The locations of the characteristics of two high-speed configurations

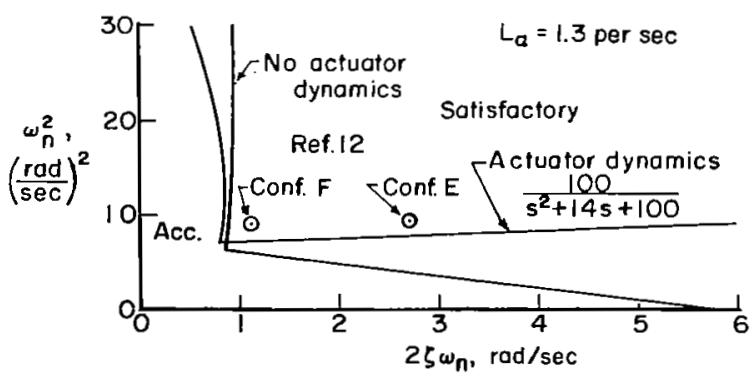

Figure 16.- Effect of actuator dynamics on attitude-control boundaries computed by using first-level pilot model (no lead) with $I_{6 x}=1.3$ per sec.

tested in reference 12 (configurations $\mathrm{E}$ and $\mathrm{F}$ ) are also presented. For configuration $\mathrm{E}$ the ratings presented in reference 12 changed from 2 to 5 with the addition of the actuator. The computations show that the configuration is well inside the satisfactory region with no actuator and just on the boundary with the $10-\mathrm{rad} / \mathrm{sec}$ actuator, so fairly good agreement exists between the computed and experimental results. For configuration $\mathbf{F}$ no 
change was noted in the experimental test results, and the computations show that this configuration falls in a region where the addition of the actuator has very little effect. Again, there is good agreement between the experimental and computed results.

\section{APPLICATIONS}

Since the pilot-model levels and the desired closed-loop system characteristics defined in the preceding sections of the paper have been shown to provide a good correlation with a very wide variety of experimentally determined pilot ratings, it is concluded that these pilot-model and closed-loop system criteria can be used to predict the pilot rating of the longitudinal handling qualities of proposed aircraft. The rating is predicted either by determining the values of the lead and lag time constants required in the pilot model to achieve the specified closed-loop characteristics or by determining if these closed-loop characteristics are achieved with a given pilot model.

It is believed that the same general procedure could be followed to determine the lateral handling qualities of an aircraft or the handling qualities of other types of vehicles. However, it might be necessary to adjust the specified closed-loop characteristics to correspond to the level of system response to which human pilots have become accustomed. This adjustment, of course, could be made by determining the best correlation with past handling-quality data for the particular type of vehicle under consideration.

\section{CONCLUDING REMARKS}

System response characteristics obtained by using pilot models have been shown to correlate with pilot ratings as follows:

(1) In the shape of the boundaries in the plots of airplane short-period characteristics

(2) In the change in pilot ratings with change in normalized lift-force derivative

(3) In the change in pilot ratings with the insertion of control-actuator dynamics

It is therefore concluded that a prediction of pilot ratings can be made by determining the level of response of the pilot required to achieve specified system characteristics. This method can also be used to compare proposed airplane designs and to provide a rational engineering interpretation of pilot comments.

Langley Research Center,

National Aeronautics and Space Administration, Hampton, Va., December 7, 1970. 


\section{APPENDIX A \\ SYSTEM PERFORMANCE DETERMINED WITH \\ PILOT TRANSFER FUNCTIONS}

Because of the great interest in predicting system performance, an example of the response of a pilot-model-aircraft system to a glide-slope command is presented. This computed time history is compared with a time history obtained from an actual flight test.

The flight-test data were taken from reference 10 and are shown in figure 17. Figure 18 was computed by using the second-level multiloop pilot model, as described in this paper, and aircraft characteristics approximately the same as those in the flighttest data of figure 17. The pilot model used also included a remnant added to the pilotmodel output. This remnant was obtained by taking a white-noise source, passing this white noise through a filter that was identical to the response characteristic of the pilot, and adding it to the output of the pilot model. The expression for the remnant is therefore $K_{n} /(1+0.2 s)^{2}$. The amplitude of the remnant $K_{n}$ was adjusted so that the meansquare value of the remnant was approximately 0.5 of the mean-square value of the total pilot-model output. It has been shown in reference 2 that a pilot remnant defined in this manner is appropriate.

The time history in figure 18 can be seen to agree well with the time history obtained from the flight tests (fig. 17). The general amplitude and frequency of the angleof-attack and pitch-angle time histories are in good agreement. One difference occurs in that the computed results show a large response at the discontinuous point in the commanded flight path, which the human pilot was able to anticipate and smooth out.
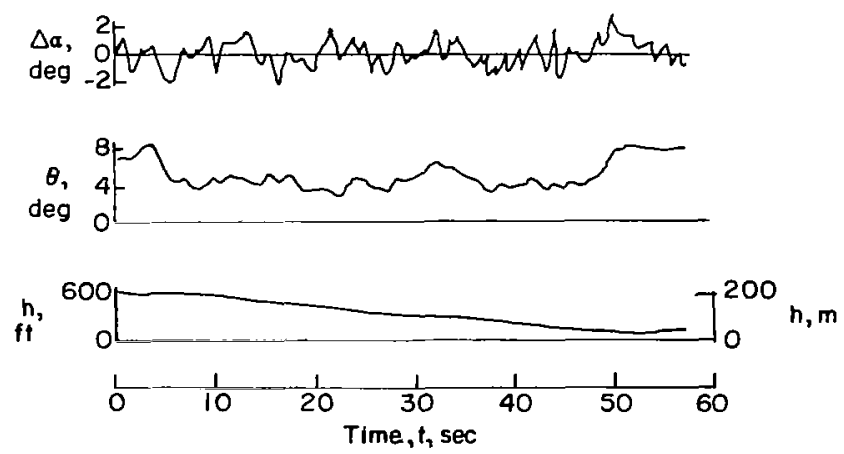

Figure 17.- Records obtained from reference 10 for flight test of a landing approach. $\omega_{n}=2.30 \mathrm{rad} / \mathrm{sec} ; \quad \zeta=0.20$. 


\section{APPENDIX A - Concluded}

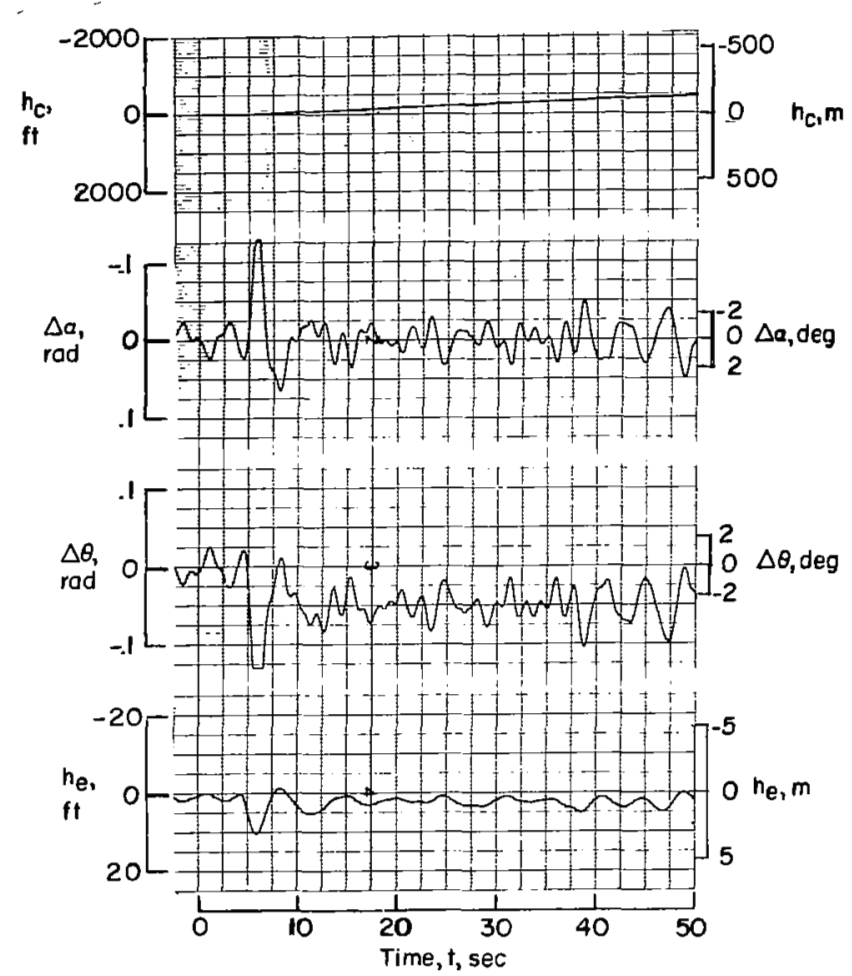

Figure 18.- Landing-approach time history computed by using second-level multiloop pilot model with remnant. $\omega_{n}=2.5 \mathrm{rad} / \mathrm{sec}$;

$\zeta=0.32$. (To facilitate comparison with fig. 17, $\Delta \alpha$ and $\Delta \theta$ are given in degrees as well as radians.)

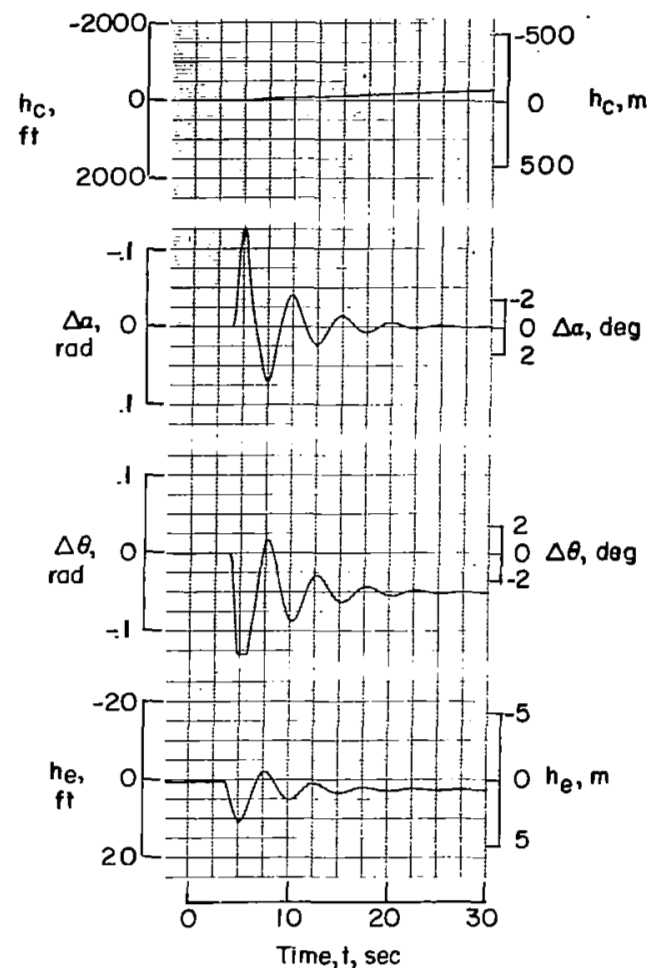

Figure 19.- Landing-approach time history computed by using second-level multiloop pilot model without remnant. $\omega_{m}=2.5 \mathrm{rad} / \mathrm{sec} ; \zeta=0.32$. (To facilitate comparison with fig. 17, $\Delta \alpha$ and $\Delta \theta$ are given in degrees as well as radians.)

To illustrate the effect of the remnant on the system response, figure 19 was computed without the remnant. The longer period, lightly damped altitude mode of motion is more apparent in figure 19 than it is in figure 18. 


\section{REFERENCES}

1. Adams, James J.; and Goode, Maxwell W.: Application of Human Transfer Functions to System Analysis. NASA TN D-5478, 1969.

2. Adams, James J.; and Bergeron, Hugh P.: A Synthesis of Human Response in ClosedLoop Tracking Tasks. NASA TN D-4842, 1968.

3. Stapleford, Robert L.; and Ashkenas, Irving L.: Effects of Manual Altitude Control and Other Factors on Short-Period Handling Quality Requirements. J. Aircraft, vol. 5, no. 1, Jan. -Feb. 1968, pp. 41-48.

4. Adams, James J.; and Bergeron, Hugh P.: Measured Variation in the Transfer Function of a Human Pilot in Single-Axis Tasks. NASA TN D-1952, 1963.

5. Adams, James J.; Kincaid, Joseph K.; and Bergeron, Hugh P.: Determination of Critical Tracking Tasks for a Human Pilot. NASA TN D-3242, 1966.

6. Adams, James J.; Bergeron, Hugh P.; and Hurt, George J., Jr.: Human Transfer Functions in Multi-Axis and Multi-Loop Control Systems. NASA TN D-3305, 1966.

7. Vinje, E. W.; and Miller, D. P.: Interpretation of Pilot Opinion by Application of Multiloop Models to a VTOL Flight Simulator Task. Third Annual NASA-University Conference on Manual Control, NASA SP-144, 1967, pp. 415-440.

8. Stapleford, Robert L.; Craig, Samuel J.; and Tennant, Jean A.: Measurement of Pilot Describing Functions in Single-Controller Multiloop Tasks. NASA CR-1238, 1969.

9. Birmingham, H. P.; and Taylor, F. V.: A Design Philosophy for Man-Machine Control Systems. Proc. IRE, vol. 42, no. 12, Dec. 1954, pp. 1748-1758.

10. Chalk, Charles R.: Flight Evaluation of Various Short Period Dynamics at Four Drag Configurations for the Landing Approach Task. FDL-TDR-64-60, U.S. Air Force, Oct. 1964. (Available from DDC as AD-608620.)

11. Hall, G. Warren: In-Flight Investigation of Longitudinal Short-Period Handling Characteristics of Wheel-Controlled Airplanes. AFFDL-TR-68-91, U.S. Air Force, Aug. 1968.

12. Parrag, Michael L.: Pilot Evaluations in a Ground Simulator of the Effects of Elevator Control System Dynamics in Fighter Aircraft. AFFDL-TR-67-19, U.S. Air Force, Sept. 1967.

13. Harper, Robert P., Jr.: Flight Evaluation of Various Longitudinal Handling Qualities in a Variable-Stability Jet Fighter. WADC Tech. Rep. 55-299, U.S. Air Force, July 1955. 
14. Montgomery, Raymond C.; and Hatch, Howard G., Jr.: Application of Differential Synthesis to Design of Multiaxis Stability Augmentation Systems. J. Aircraft, vol. 6, no. 4, July-Aug. 1969, pp. 336-343.

15. Chalk, Charles R.: Fixed-Base Simulator Investigation of the Effects of $L_{\alpha}$ and True Speed on Pilot Opinion of Longitudinal Flying Qualities. ASD-TDR-63-399, U.S. Air Force, Nov. 1963. 